\title{
Dual left anterior descending coronary artery (type III) and the presence of myocardial bridges: a post-mortem examination
}

\author{
G. Wróbel ${ }^{1}$, M. Spałek ${ }^{1,2}$, J. Spałek ${ }^{3}$, T. Kuder ${ }^{1}$ \\ ${ }^{1}$ Department of Anatomy, Institute of Medical Sciences, Collegium Medicum, \\ Jan Kochanowski University, Kielce, Poland \\ ${ }^{2}$ Radiology and Diagnostic Imaging Department, Swietokrzyskie Oncology Centre, Kielce, Poland \\ ${ }^{3}$ Collegium Medicum, Jan Kochanowski University, Kielce, Poland
}

[Received: 13 August 2019; Accepted: 26 September 2020]

An observational examination of the heart was performed in the Department of Anatomy, during the routine autopsy of an 89-year-old man. The heart was fixed in 10\% formalin and an analysis of arterial vasculature was performed (used morphometric abbreviations below [mm]: L — length; D - diameter of origin). Trifurcation of the left main coronary artery $(L=17.4 ; D=8.1)$ was observed during the study, which originated in the left aortic sinus and was followed by three branches: proper left anterior descending artery ( $L L A D ; L=11.2$; $D=7.4)$, intermediate branch $(L=98.6 ; D=3.5)$ and left circumflex artery $(L=104.2 ; D=4.9)$, respectively. In the $P L A D$ division, there was noted $L A D 1$ (long) which was running in the interventricular septum $(L=32.2)$ and further in the subepicardial segment $(L=109.3)$ in the anterior interventricular groove towards the apex (AC) (LAD1; $L=141.4 ; D=6.3$ ) and $L A D 2$ (short) running subepicardial in the anterior interventricular groove in the AC direction (LAD2; $L=68.4 ; D=3.2)$. Four diagonal branches $(D B)$ and 9 septal perforators (SP) were observed in the course of $L A D 1$; regarding the $L A D 2$ there were 6 SP only. It is worth noting that the first SP supplying the interventricular septum came from $L A D 2$. Another interesting aspect of the observation was the occurrence of 4 myocardial bridges on the LAD1, LAD2, DB1 arteries and on the second obtuse marginal branch (OM2), respectively.

This case describes a rare anatomical anomaly of the $L A D$ course and reminds clinicians of the need for careful planning of cardiac surgeries and percutaneous interventions on the coronary arteries. (Folia Morphol 2020; 79, 3: 634-639)

Key words: left coronary artery, dual left anterior descending coronary artery (type III), anatomical variation, morphometry, myocardial bridges

\section{INTRODUCTION}

Anatomical variants of the coronary arteries are usually detected as ancillary findings during imaging or autopsy [26]. General variability in the coronary system of the heart, related to its various vessels, is characterised by a low incidence in the range of $0.13-1.3 \%$ [5, 28, 33]. Agarwal and Kazerooni [1] using computed tomography examinations showed

Address for correspondence: Dr. G. Wróbel, Department of Anatomy, Institute of Medical Sciences, Collegium Medicum, Jan Kochanowski University, Aleja IX Wieków Kielc 19, 25-317 Kielce, tel: +48 41349 6965, fax: +48 4134969 16, e-mail: grzegorz.wrobel@ujk.edu.pl 
the incidence of variability in the dual left anterior descending artery (LAD) at the level of $0.29 \%(2 / 670)$. Bozlar et al. [6] recorded the incidence (dual LAD) at the level of $4 \%(56 / 1337)$, including LAD type III at the level of $0.22 \%$ (3/1337). In another study, Nikolić et al. [23] performed a coronary artery analysis on hearts collected from human cadavers in order to assess the protective role of myocardial bridges (MB) in the development of atherosclerotic lesions in the coronary parts below the bridge, and showed the frequency of LAD type III to be $0.28 \%$ (10/3500), which concerned only men. It can therefore be assumed that dual LAD is one of the rarest coronary anomalies [6]. According to some literature data, coronary artery anomalies are among the most common cardiovascular causes in the case of sudden death in young patients [11]. It is worth noting that the clinical impact of variability within angioarchitectonics of coronary arteries depends on the ability of "atypical" arteries to supply the relevant areas of the heart with blood [30].

\section{CASE REPORT}

A cardiac observational study was carried out at the Department of Anatomy, during a routine autopsy for teaching purposes as part of a conscious body donation programme. The heart, collected from the cadaver of an 89-year-old man, underwent preservation in $10 \%$ formalin, followed by the analysis of arterial vascularisation. To measure the length of the vessels, a digital calliper was used, equipped with an LCD display (Mitutoyo, Japan, accuracy up to $0.02 \mathrm{~mm}$ ). Straight sections of the arteries were measured by placing the fixed jaw of the calliper at the beginning of the vessel section and the sliding jaw at its end. In the case of curvilinear arteries, the measurement was performed indirectly using silky, non-absorbable suture thread (Péters Surgical), in which the thread was first placed along the course of the artery to establish the length and then measured with the calliper to obtain the length. Using the same calliper, the external diameters of the arteries at the initial points of branching of these vessels were also measured as well as the depth level in the myocardium.

The coronary artery observations were that left main coronary artery (LMCA) trifurcation was observed, its origin was the left aortic bay (LSV), and its subsequent course ended with the emergence of three branches, respectively: the proper left anterior descending artery ( $p L A D)$, the intermediate branch
(IMB) and the left circumflex artery (LCXA) (Fig. 1A). The LMCA length was $17.4 \mathrm{~mm}$, while its diameter at the point of branching from the aorta was $8.1 \mathrm{~mm}$. In the right direction, from the LMCA trifurcation, a pLAD was created (the diameter at the point of its origin was $7.4 \mathrm{~mm}$ ) (Fig. 1B), whose course at a distance of $11.2 \mathrm{~mm}$ from the trifurcation point was divided into two vessels:

- LAD1 (long); over a distance of $32.2 \mathrm{~mm}$ it runs intramuscularly in the interventricular septum and further subepicardially in the anterior interventricular sulcus $(109.3 \mathrm{~mm}$ ) toward the apex cordis (AC) - total length of $141.4 \mathrm{~mm}$, diameter at the division point of the PLAD was $6.3 \mathrm{~mm}$;

- LAD2 (short); it runs over a distance of $18.3 \mathrm{~mm}$ intramuscularly in the interventricular septum, and further subepicardially in the anterior interventricular sulcus towards the $A C$ - total length of $68.4 \mathrm{~mm}$, diameter at the division point from the PLAD was $3.2 \mathrm{~mm}$.

Over the course of LAD1, 4 diagonal branches (DBs) responsible for the vascularisation of the anterior wall of the left ventricle and 9 septal perforators (SP) were observed, whereas in the case of LAD2 there were 6 SPs (Fig. 1B); in total, the vascularisation of the anterior part of interventricular septum corresponded to 15 SPs from LAD1 and LAD2. It is also worth noting that the first SP vascularising the interventricular septum was from LAD2. From the Figures $1 A$ and $1 B$, it can be concluded that $D B 1$, $D B 2, L A D 1$, and $L A D 2$ are originated from the PLAD trunk together; however, a thorough analysis of this case from every perspective allows to state that DB1 and $D B 2$ are vessels derived from LAD1.

From the LMCA, an LCXA with a diameter of $4.9 \mathrm{~mm}$ arises. It ran to the left, towards the coronary groove, while its length was $104.2 \mathrm{~mm}$. Regarding the distance from the trifurcation point (PT), the following branches were observed in the course of LCXA: atrial branch (AB) at a distance of $6.2 \mathrm{~mm}$, the first artery of the obtuse margin (OM1) at a distance of $26.4 \mathrm{~mm}$ and the second artery of the obtuse margin (OM2) at a distance of $31.7 \mathrm{~mm}$ (Fig. 1A). The terminal section of the LCXA was the posterolateral branch (PL) terminating at the lower surface of the left ventricle (Fig. 2B).

An additional IMB between PLAD and LCXA extending in the anterolateral direction was observed. At the PT, the diameter of this artery was $3.5 \mathrm{~mm}$, over a distance of $27.2 \mathrm{~mm}$ it ran subepicardially, while further over a distance of $71.4 \mathrm{~mm}$ the artery 


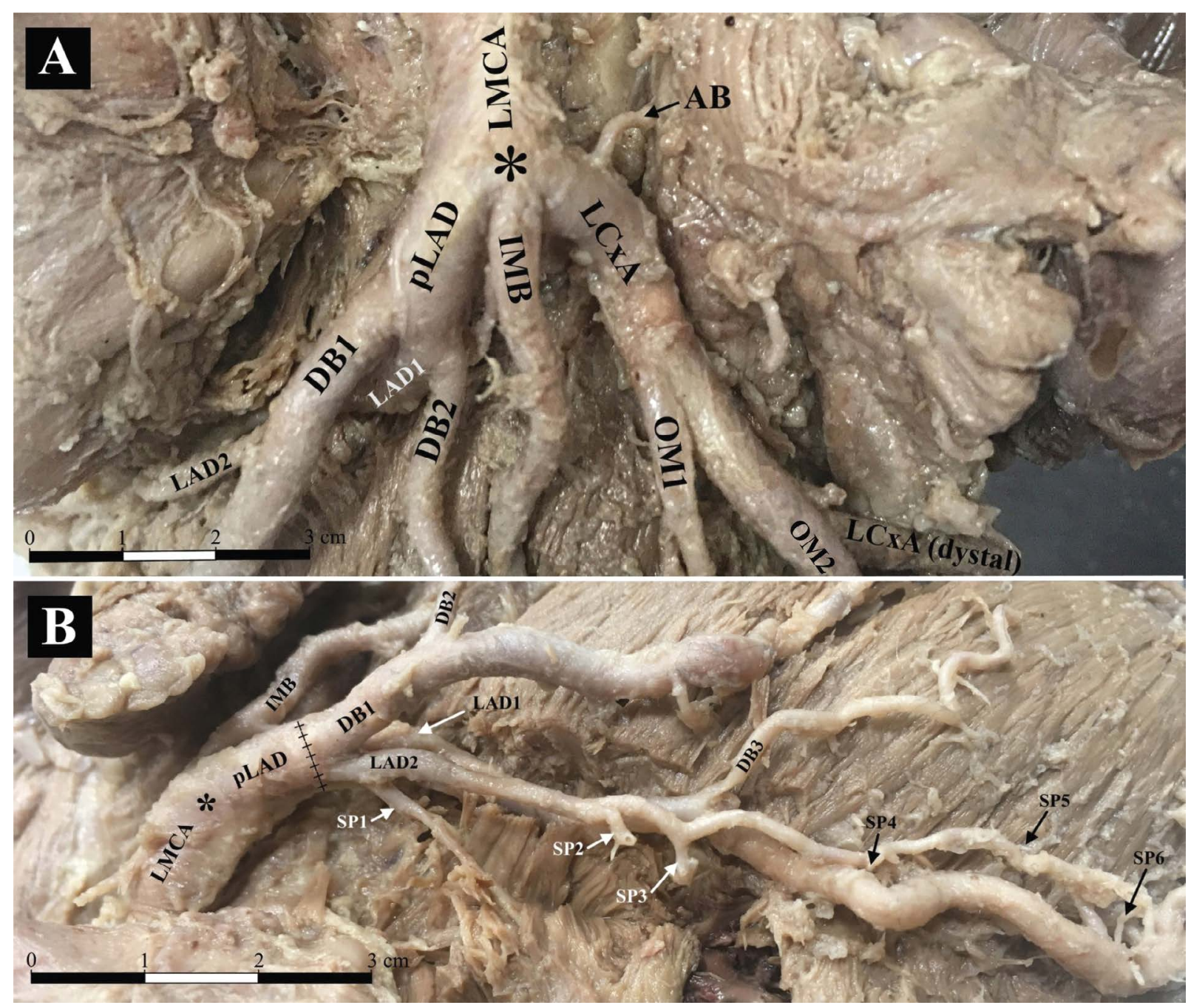

Figure 1. A. Trifurcation of left coronary artery; B. Origin and course of left anterior descending artery (short) and presence six septal perforators; LMCA — left main coronary artery; pLAD — proper left anterior descending; IMB — intermediate branch; LCxA — left circumflex artery; LAD1 — left anterior descending (long); LAD2 — left anterior descending (short); DB1-3 — diagonal branch first, second and third; OM1-2 — obtuse marginal branches (first and second); SP1-6 - septal perforators (from one to six); AB — atrial branch; *trifurcation point; ++++ pLAD dividing line.

ran intramuscularly; the total length of this artery was $98.6 \mathrm{~mm}$ (Fig. 1B). Another interesting aspect of the observation was the occurrence of $4 \mathrm{MB}$ on the LAD1, LAD2, DB1 and OM2 arteries, respectively (Fig. 2A, B). Table 1 shows the length of the $M B$, the distance from the artery origin to the $M B$, the depth of the MB, i.e. the thickness of the muscle tissue band that ran over the coronary artery and the diameters before and after the myocardial bridge.

\section{DISCUSSION}

In terms of anatomy, the LAD arises from the LMCA, runs in the anterior interventricular sulcus (AIS) towards the apex cordis and gives diagonal and septal branches that penetrate the inter- ventricular septum, while the diagonal branches extend to the anterior wall of the left ventricle, and sometimes to the anterior wall of the right ventricle (diagonal right ventricle) [1]. The occasional dual LAD (in the range of $0.13-4 \%[6,28]$ is characterised by the presence of two distinct vessels in the AIS and usually results in a short LAD ending in the proximal part of the AIS and a long LAD artery that proximally extends beyond the AIS, but ends in the distal part of the AIS. Coronary artery anomalies, including dual $L A D$, are very interesting both scientifically and clinically. In 1983, Spindola-Franco et al. [29] proposed a classification and divided them into four types. In types I-III, the LMCA gives rise to a common 

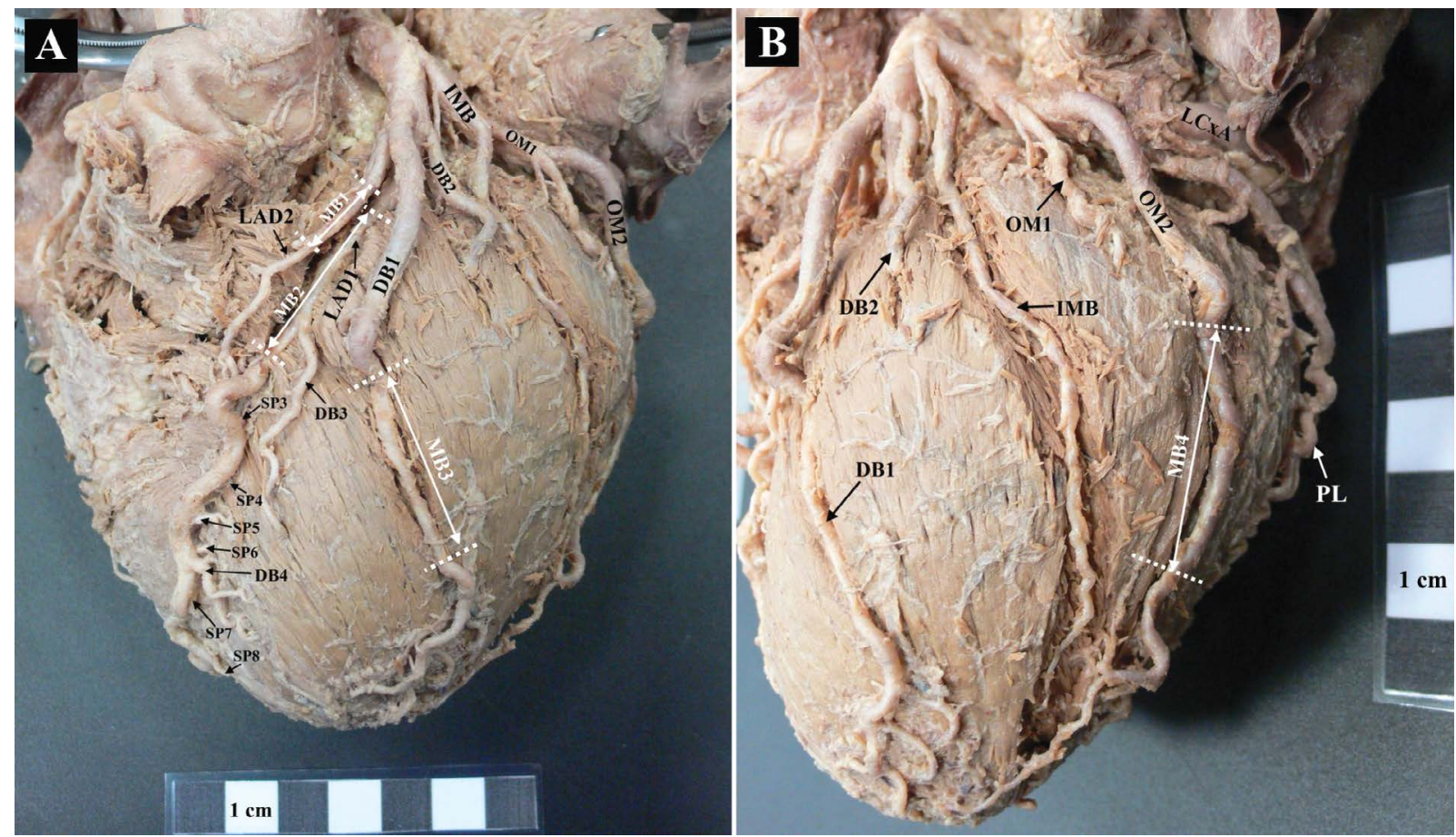

Figure 2. A. View of the anterior wall of the left heart ventricle (dissected); B. View of the anterolateral wall of the left heart ventricle (dissected); IMB — intermediate branch; LCxA — left circumflex artery; LAD1 — the first left anterior descending (long); LAD2 — the second left anterior descending (short); DB1-3 - diagonal branch first, second and third; 0M1-2 - obtuse marginal branches (first and second); SP3-8 - septal perforators (from the third to the eighth); MB1-4 — myocardial bridges (from one to four); PL — posterolateral branch.

Table 1. Measurements $[\mathrm{mm}]$ of myocardial bridges $(\mathrm{MB})$ and diameters of their underlies arteries

\begin{tabular}{lccccc}
\hline Coronary artery branch & Length of MB & Thickness of MB & Distance from the origin & Pre-bridge diameter (D1) & Post-bridge diameter (D2) \\
\hline LAD1 & 32.2 & 8.1 & 13.3 & 6.2 & 5.9 \\
LAD2 & 18.3 & 4.4 & 8.2 & 3.1 & 2.9 \\
DB1 & 38.3 & 3.1 & 58.9 & 3.4 & 3.0 \\
OM2 & 42.3 & 1.9 & 44.6 & 3.3 & 2.8 \\
\hline
\end{tabular}

LAD1 — left anterior descending (long); LAD2 — left anterior descending (short); DB1 — diagonal branch first; OM2 — obtuse marginal branches

(proper) LAD, which is then divided into a short and long LAD. In types I-III, the end of the short LAD is in the proximal part of the AIS, whereas the end of the long LAD is in the distal part of the AIS. The differences between types I-III relate to the course of the proximal part of the long LAD: in type I a subepicardial course on the left side of the proximal part of AIS, type II - a subepicardial course on the right side of the proximal part of AIS, type III an intramuscular course in the interventricular septum. In type IV, the short LAD arises from the LMCA and its end is in the proximal part of the AIS, while the long LAD arises from the proximal part of the right coronary artery and proximally it runs subepicardially in the front of the right ventricular outflow tract and terminates in the distal part of the AIS.
Taking this division into account, the described case of the dual LAD should be classified as type III. In recent years, six types of dual LAD have been reported $[17,18]$. In the latest studies, Boznar et al. [6] distinguished 9 types of dual LAD, Celik et al. [8] showed a tenth type of dual LAD, while Al-Umairi et al. [3] noted an eleventh type of dual LAD. It is worth noting that most of the new studies on dual LAD are based on imaging studies.

Despite the changes in the classification, where 4 types were initially distinguished, and currently 11 types are given, some dual LAD types show a very low frequency of occurrence, as in the case of the type III dual LAD. According to the original classification proposed by Spindola-Franco et al. [29], this type is characterised by a proximal intramuscular course of the long LAD. 
In the literature, there are few studies on the morphometric aspects of the type III dual LAD based on post-mortem studies. Nikolić et al. [23], analysing the vascularisation of 3500 hearts over 12 years of research, showed ten cases of type III dual LAD. The vast majority of studies on this type of dual LAD come from morphological case studies, while the original works are based on radiological studies. The average LMCA lengths in the literature show high variability $[14,16,25]$. Miklaszewska et al. [20] give an average LMCA length of $17 \mathrm{~mm}$, whereas for LAD - an average length of $137.6 \mathrm{~mm}$. Usually in the larger hearts there is a longer left coronary artery $[13,14]$.

The MB in the heart are muscle tissue bands running over the coronary arteries, which during the contraction of the cardiac muscle exert pressure on the blood vessel and thus affect the narrowing of its lumen and, consequently, the impairment of its blood flow. Already in the eighteenth century, this type of anomaly was described, but it was only in the 1960s that more attention was paid to the occurrence of $M B$ and their clinical significance [27].

The range of the incidence of $M B$ is wide and related to research methodology. As it results from the literature data, in the imaging studies the presence of $\mathrm{MB}$ in the range of $0.5-16 \%$ of the cases studied $[4,15,24]$ is observed, whereas in the autopsy studies there is a much more frequent occurrence of $M B$, in the range of $15-86 \%[7,12,21]$. The presence of $M B$ can be observed in relation to any coronary artery; however, the majority - $70 \%$ to $98 \%$ - concern LAD [9, 31]. Nasr [22], in his studies on hearts from 60 human cadavers, showed the presence of MB in $27(45 \%)$ hearts, mainly in the central segment of the anterior interventricular artery (52.8\%) and to a lesser extent in its diagonal branch (13.8\%), the posterior interventricular artery $(13.8 \%)$, and the middle and left marginal branch (5.6\%). In the study cited, the average length of MBs was $24.9 \pm 1.98 \mathrm{~mm}$, and their thickness was $2.28 \pm 0.13 \mathrm{~mm}$, while the average distance from the artery origin to the MB in male hearts was $44.5 \pm 2.5 \mathrm{~mm}$; in the case of vascular diameters before and after the MB, Nasr [22] noted (in male hearts) the mean variability for LAD $(3.2 \pm$ $\pm 0.28 \mathrm{~mm}$ vs. $3.02 \pm 0.12 \mathrm{~mm})$ and $\mathrm{DB}(2.54 \pm$ $\pm 0.16 \mathrm{~mm}$ vs. $2.42 \pm 0.14 \mathrm{~mm}$ ). Nikolić et al. [23], when examining MB occurring in type III dual LAD, recorded their length in the range of 7-35 $\mathrm{mm}$, and a thickness in the range of 3-6 $\mathrm{mm}$. In this case, they were quite long bridges, from $18.26 \mathrm{~mm}$ on LAD1 to
$42.25 \mathrm{~mm}$ on OM2; their thickness was in the range of $1.89 \mathrm{~mm}$ on OM2 to $8.09 \mathrm{~mm}$ on LAD1. According to the literature data, the clinical significance of MB is not clearly specified, there are studies in which patients with MB may function asymptomatically, but may also have coronary spasms, thrombosis and coronary dissection potentially associated with the presence of $M B[10,19,31,32]$. Some authors indicate that due to the fact that the majority of coronary flow takes place in the end-diastolic phase, the presence of MB does not significantly impede blood supply to the myocardium [2]. This case cannot be used to discuss this issue, because there is no clinical data regarding the examined person.

\section{CONCLUSIONS}

The mere occurrence of a dual LAD usually does not manifest clinically, but the diagnosis of this rare anomaly is important, because it may be misleading during clinical diagnosis as well as of postoperative complications. This case describes the rare anatomical variability in the course of the LAD, which is a valuable source of information for clinicians, especially in surgical planning and cardiosurgical intervention.

\section{Funding}

This work was supported under the programme of the Minister of Science and Higher Education under name "Regional Initiative of Excellence in 2019-2022 project number: 024/RID/2018/19, financing amount: $11,999,000.00$ PLN".

\section{REFERENCES}

1. Agarwal PP, Kazerooni EA. Dual left anterior descending coronary artery: CT findings. AJR Am J Roentgenol. 2008; 191(6): 1698-1701, doi: 10.2214/AJR.08.1193, indexed in Pubmed: 19020238.

2. Alegria JR, Herrmann J, Holmes DR, et al. Myocardial bridging. Eur Heart J. 2005; 26(12): 1159-1168, doi: 10.1093/ eurheartj/ehi203, indexed in Pubmed: 15764618.

3. Al-Umairi RS, Al-Kindi FA, Al-Tai SA. A new variant of dual left anterior descending artery anomaly: type XI. Sultan Qaboos Univ Med J. 2018; 18(3): e386-e388, doi: 10.18295/ squmj.2018.18.03.021, indexed in Pubmed: 30607284.

4. Angelini P, Trivellato M, Donis J, et al. Myocardial bridges: a review. Prog Cardiovasc Dis. 1983; 26(1): 75-88, doi: 10.1016/0033-0620(83)90019-1, indexed in Pubmed: 6346395.

5. Angelini P, Velasco JA, Flamm S. Coronary anomalies: incidence, pathophysiology, and clinical relevance. Circulation. 2002; 105(20): 2449-2454, doi: 10.1161/01. cir.0000016175.49835.57, indexed in Pubmed: 12021235.

6. Bozlar U, Uğurel MŞ, Sarı S, et al. Prevalence of dual left anterior descending artery variations in $\mathrm{CT}$ angiography. 
Diagn Interv Radiol. 2015; 21(1): 34-41, doi: 10.5152/ dir.2014.14275, indexed in Pubmed: 25333217.

7. Burnsides C, Edwards JC, Lansing Al, et al. Arteriosclerosis in the intramural and extramural portions of coronary arteries in the human heart. Circulation. 1956; 13(2): 235-241, doi: 10.1161/01.cir.13.2.235, indexed in Pubmed: 13356383.

8. Celik T, Bozlar U, Ozturk C, et al. A new anomaly of the left anterior descending artery: Type $X$ dual LAD. Indian Heart J. 2015; 67 (Suppl 3): S14-S17, doi: 10.1016/j. ihj.2015.09.004, indexed in Pubmed: 26995420.

9. Ciçek D, Kalay N, Müderrisoğlu H. Incidence, clinical characteristics, and 4-year follow-up of patients with isolated myocardial bridge: a retrospective, single-center, epidemiologic, coronary arteriographic follow-up study in southern Turkey. Cardiovasc Revasc Med. 2011; 12(1): 25-28, doi: 10.1016/j. carrev.2010.01.006, indexed in Pubmed: 21241968.

10. Desseigne $P$, Tabib A, Loire R. Myocardial bridging on the left anterior descending coronary artery and sudden death. Apropos of 19 cases with autopsy. [Article in French]. Arch Mal Coeur Vaiss. 1991; 84(4): 511-516.

11. Eckart RE, Scoville SL, Campbell CL, et al. Sudden death in young adults: a 25-year review of autopsies in military recruits. Ann Intern Med. 2004; 141(11): 829-834, doi: 10.7326/0003-4819-141-11-200412070-00005, indexed in Pubmed: 15583223.

12. Ferreira AG, Trotter SE, König B, et al. Myocardial bridges: morphological and functional aspects. Br Heart J. 1991; 66(5): 364-367, doi: 10.1136/hrt.66.5.364, indexed in Pubmed: 1747296.

13. Karaca M, Kirilmaz A, Oncel G, et al. Contrast-enhanced 64-slice computed tomography in detection and evaluation of anomalous coronary arteries. Tohoku J Exp Med. 2007; 213(3): 249-259, doi: 10.1620/tjem.213.249, indexed in Pubmed: 17984622.

14. Lee WJ. Segmental anatomy of coronary arteries. Radiology. 2007; 244(1): 319, doi: 10.1148/radiol.2441061365, indexed in Pubmed: 17581916.

15. Lee MS, Chen $\mathrm{CH}$. Myocardial bridging: an up-to-date review. J Invasive Cardiol. 2015; 27(11): 521-528, indexed in Pubmed: 25999138.

16. Leung WH, Stadius ML, Alderman EL. Determinants of normal coronary artery dimensions in humans. Circulation. 1991; 84(6): 2294-2306, doi: 10.1161/01.cir.84.6.2294, indexed in Pubmed: 1959185.

17. Manchanda A, Qureshi A, Brofferio A, et al. Novel variant of dual left anterior descending coronary artery. J Cardiovasc Comput Tomogr. 2010; 4(2): 139-141, doi: 10.1016/j. jcct.2009.12.007, indexed in Pubmed: 20430346.

18. Maroney J, Klein LW. Report of a new anomaly of the left anterior descending artery: type VI dual LAD. Catheter Cardiovasc Interv. 2012; 80(4): 626-629, doi: 10.1002/ ccd.23219, indexed in Pubmed: 21953811.

19. Migliore F, Maffei E, Perazzolo Marra M, et al. LAD coronary artery myocardial bridging and apical ballooning syndrome. JACC Cardiovasc Imaging. 2013; 6(1): 32-41, doi: 10.1016/j. jcmg.2012.08.013, indexed in Pubmed: 23328559.

20. Miklaszewska D, Gawlikowska-Sroka A, Czerwiński F. Morphometric study of the left coronary artery. [Article in Polish]. Ann Acad Med Stetin. 2010; 56(2): 12-17.
21. Möhlenkamp S, Hort W, Ge J, et al. Update on myocardial bridging. Circulation. 2002; 106(20): 2616-2622, doi: 10.1161/01.cir.0000038420.14867.7a, indexed in Pubmed: 12427660.

22. Nasr AY. Myocardial bridge and coronary arteries: morphological study and clinical significance. Folia Morphol. 2014; 73(2): 169-182, doi: 10.5603/FM.2014.0025, indexed in Pubmed: 24902096.

23. Nikolić S, Živković V, Gačić Manojlović E, et al. Does the myocardial bridge protect the coronary from atherosclerosis? A comparison between the branches of the dual-left anterior descending coronary artery type 3: an autopsy study. Atherosclerosis. 2013; 227(1): 89-94, doi: 10.1016/j.atherosclerosis.2012.12.010, indexed in Pubmed: 23312783.

24. Noble J, Bourassa MG, Dyrda I, et al. Myocardial bridging and milking effect of the left anterior descending coronary artery: normal variant or obstruction? Am J Cardiol. 1976; 37(7): 993-999, doi: 10.1016/0002-9149(76)90414-8, indexed in Pubmed: 1274883.

25. Ollivier JP, Droniou J. Anatomy and lesions of the coronary system. Comparative data on 100 consecutively examined patients under 35 and over 45. [Article in French]. Ann Med Interne (Paris). 1984; 135(3): 189-193.

26. Oncel G, Oncel D. A rare coronary artery anomaly: double left anterior descending artery. J Clin Imaging Sci. 2012; 2: 83, doi: 10.4103/2156-7514.105150, indexed in Pubmed: 23393639 .

27. Porstmann W. Intramural coronary vessels in the angiogram. [Article in German]. Fortschr Geb Rontgenstr Nuklearmed. 1960; 92: 129-133.

28. Sajja LR, Farooqi A, Shaik MS, et al. Dual left anterior descending coronary artery: surgical revascularization in 4 patients. Tex Heart Inst J. 2000; 27(3): 292-296, indexed in Pubmed: 11093416.

29. Spindola-Franco H, Grose R, Solomon N. Dual left anterior descending coronary artery: angiographic description of important variants and surgical implications. Am Heart J. 1983; 105(3): 445-455, doi: 10.1016/00028703(83)90363-0, indexed in Pubmed: 6829406.

30. Talanas G, Delpini A, Casu G, et al. A double left anterior descending coronary artery emerging from the right Valsalva sinus: a case report and a brief literature review. J Cardiovasc Med (Hagerstown). 2009; 10(1): 64-67, doi: 10.2459/jcm.0b013e3283189350, indexed in Pubmed: 19708227.

31. Tarantini G, Migliore F, Cademartiri F, et al. Left anterior descending artery myocardial bridging: a clinical approach. J Am Coll Cardiol. 2016; 68(25): 2887-2899, doi: 10.1016/j. jacc.2016.09.973, indexed in Pubmed: 28007148.

32. Wu S, Liu W, Zhou Y. Spontaneous coronary artery dissection in the presence of myocardial bridge causing myocardial infarction: an insight into mechanism. Int J Cardiol. 2016; 206: 77-78, doi: 10.1016/j.ijcard.2016.01.085, indexed in Pubmed: 26780679.

33. Yamanaka O, Hobbs RE. Coronary artery anomalies in 126,595 patients undergoing coronary arteriography. Cathet Cardiovasc Diagn. 1990; 21(1): 28-40, doi: 10.1002/ ccd.1810210110, indexed in Pubmed: 2208265. 